Congestive cardiomyopathy is sometimes so closely related to parturition that "peripartal" cardiomyopathy has been regarded as a specific entity, but possibly the pregnancy is simply a precipitating factor in a woman with an already susceptible myocardium. ${ }^{8}$ Lactation, malnutrition, and low socio-economic status also appear to have a role in its causation. Cardiomyopathy is thus relatively rarely related to pregnancy in Britain but is more commonly so in Africa, in American negroes in the Southern States, ${ }^{9}$ and in the West Indies. ${ }^{10}$

Doubt also surrounds the role of alcohol in causing the disease, for cardiac dysfunction is rare in patients with alcoholic cirrhosis, alcoholism is common, and the pathological changes are nonspecific. Impaired oxidative metabolism from thiamine deficiency and the recently discovered toxic effect of cobalt added to beer as a froth stabilizer can lead to myocardial failure, but a direct toxic effect of alcohol is also thought to be a relatively common cause of cardiomyopathy. ${ }^{11}$ Cobalt and antimony are myocardial poisons, but in most cardiomyopathies the link between the mechanical failure and the biochemical fault is still missing. Even after histochemical and electron-microscopic examination the myocardium shows little evidence of the gross functional abnormality which caused death.

We are a long way from understanding these disorders of the heart muscle, and world-wide co-operative effort is needed if progress is to be made. Meanwhile Professor Shaper and his colleagues are to be congratulated on providing a useful review of this puzzling group of diseases.

\section{Gastric and Oesophageal Cancer in the Welsh}

In the causation of disease both genetic and environmental factors are often at work, but the proportions of their contributions vary widely from one disease to another. Cancer is like other diseases in this respect.

During recent years evidence for the importance of environmental factors has come to the fore in the aetiology of several types of cancer, including cancers of the stomach and oesophagus. Notable in this respect are the studies by W. Haenszel and his colleagues on migrants. ${ }^{12}$ The most recent of these ${ }^{3}$ refers to Japanese who migrate to the United States or Hawaii. The standardized mortality ratio for cancer of the stomach in U.S. white males is 17 compared with 100 for Japanese males in Japan. In Japanese male migrants it is 72 and for their sons, born in the adoptive country, it is 38. The figures for cancer of the stomach in Japanese women migrants and U.S.-born Japanese females show the same trends. The figures for oesophageal cancer in males also indicate that the environment of the United States is less conducive to the development of cancer than is that of Japan. The data for cancers of the oesophagus in females were too few for analysis. Growing knowledge of agents that are or may be present in the environment and that may theoretically cause gastric or oesophageal cancer in $\operatorname{man}^{4}$ has also helped to make genetic factors seem relatively unimportant. The possible importance of exposure to tobacco and alcohol ${ }^{5}$ and to nitrosamines in home-brewed alcoholic beverages ${ }^{6}$ deserves special mention in this regard.

Against this trend come two papers from D. J. B. Ashley at the Morriston Hospital, Swansea. ${ }^{-8}$ The first is concerned with oesophageal cancer in Wales. Calculations based on the data for England and Wales indicate that the standardized mortality ratios for cancer of the oesophagus in Wales during 1958-63 were 117 for males and 164 for females (England and Wales $=100) .^{9}$ Subdivision of the inhabitants of the principality into "High," "Intermediate," and "Low" Welsh on the basis of ability to speak the Welsh language and possession of a Welsh or non-Welsh surname indicated an increasing risk of oesophageal cancer with increasing Welshness in both sexes, but particularly in females. Ashley rejects the suggestion that iron deficiency is likely to be the cause and considers that a genetic factor is involved, possibly a gene on the $\mathrm{X}$ chromosome.

Ashley's second paper $^{8}$ is concerned with the incidence of gastric cancer in Wales. Again the disease is more prevalent in the principality than in England, but the apparent association between risk of the disease and increasing Welshness is less marked than for cancer of the oesophagus. If a genetic factor is responsible it does not seem to be related to bloodgroup-determining genes, since there is no excess of blood group $\mathrm{A}$ among persons with Welsh surnames. ${ }^{9}$

The value of studies such as Ashley's is not that they define cause-and-effect relationships but that they stimulate more definitive studies. In the present case a close look at the incidence of cancers of the oesophagus and stomach in Welsh persons who have migrated from the environment of Wales is clearly indicated. The evidence for a genetic influence would be greatly strengthened by showing that Welshness, irrespective of residence in Wales, carried an increased risk of developing the cancers in question. At the same time a closer search for special features in the environment of Wales is indicated. Studies on the relationship between soil and the risk of stomach cancer have so far failed to point clearly to a definable aetiological factor. Meanwhile the need stressed previously in these columns ${ }^{10}$ to investigate theories based on epidemiological surveys by experimental studies on laboratory animals remains.

1 Haenszel, W., fournal of the National Cancer Institute, 1961, 26, 37. 2 Staszewski, J., and Haenszel, W., Fournal of the National Cancer Institute, 1965, 35, 291.

${ }^{3}$ Haenszel, W., and Kurihara, M., Fournal of the National Cancer Institute, 1968, 40, 43.

- Stewart, H. L., Proceedings of the 9 th International Cancer Conference, pp. 15-49, 1967, ed. by R. J. C. Harris. Berlin, Springerference,

5 Wynder, E. L., Bross, I. J., and Feldman, R. M., Cancer, 1957, 10, 1300 .

- McGlashan, N. D., Walters, C. L., and McLean, A. E. M., Lancet, $1968,2,1017$.

7 Ashley, D. J. B., Fournal of Medical Genetics, 1969, 6, 70.

8 Ashley, D. J. B., Fournal of Medical Genetics, 1969, 6, 76.

- Ashley, D. J. B., and Davies, H. D., fournal of Medical Genetics, 1966, 3, 203.

10 British Medical fournal, 1965, 1, 1. 